\title{
Antiepileptic drugs patterns in elderly inpatients in a Brazilian tertiary center, Salvador, Brazil
}

\author{
Uso de drogas antiepilépticas em idosos internados em centro terciário, Salvador, Brasil \\ Telma Rocha de Assis', Osvaldo J. M. Nascimento ${ }^{2}$, Gersonita Costa ${ }^{1}$, Aroldo Bacellar ${ }^{1}$
}

\begin{abstract}
Epilepsy is very prevalent among elderly inpatients and treatment is far from ideal. Objective: To analyze prescribing patterns of antiepileptic drugs (AEDs) for hospitalized elderly with epilepsy, their relations with comorbidities and comedications. Method: We assessed prescription regimen of elderly patients that were under AED use for treatment of epileptic seizures, during hospitalization. One hundred and nine patients were enrolled. AED regimen was categorized into two groups: Group 1 defined as appropriate (carbamazepine, oxcarbazepine, valproic acid, gabapentin, clobazan and lamotrigine) and Group 2 as inappropriate (phenytoin and phenobarbital). Results: We found $73.4 \%$ of patients used inappropriate AEDs $(p<0.001)$. Monotherapy was prescribed for $71.6 \%$ of patients. The most common comorbidity was hypertension. Potentially proconvulsant drugs as comedications were used for nearly half of patients. Conclusion: Inappropriate AED therapy was commonly prescribed regimen for elderly inpatients. Some recommendations are discussed for a better care of elderly inpatients with epilepsy.
\end{abstract}

Keywords: antiepileptic drugs, elderly, epilepsy, epileptic seizures.

RESUMO

Epilepsia é frequente entre idosos hospitalizados e o tratamento costuma ser aquém do ideal. Objetivo: Analisar os padrões de prescrição de drogas antiepilépticas para idosos hospitalizados com epilepsia, bem como sua relação com comorbidades e comedicações. Método: Revisamos os prontuários de pacientes idosos internados com diagnóstico de epilepsia e que estavam em uso de droga antiepiléptica (DAE) durante o período de hospitalização. Cento e nove pacientes foram incluídos no estudo. 0 regime de DAE foi categorizado em dois grupos: Grupo 1, definido como apropriado (carbamazepina, oxcarbazepina, ácido valpróico, gabapentina, clobazam e lamotrigina) e Grupo 2, como inapropriado (fenitoína e fenobarbital). Resultados: $73,4 \%$ dos pacientes usaram DAE inapropriadas ( $p<0,001$ ). Regime de monoterapia foi usado por $71,6 \%$ dos pacientes. Hipertensão arterial foi a comorbidade mais frequente. Medicações concomitantes potencialmente proconvulsivantes foram usadas por quase metade desta população. Conclusão: Regime de droga antiepiléptica inapropriada foi o mais utilizado em pacientes idosos internados. São discutidas algumas recomendações para melhor cuidado ao paciente idoso hospitalizado com epilepsia.

Palavras-chave: drogas antiepilépticas, idosos, epilepsia, crises epilépticas.

Epilepsy is a common serious chronic neurological condition of the central nervous system (CNS) leading to poor quality of life and substantial morbidity and mortality ${ }^{1}$. It is the third most frequent neurological disorder in the elderly following stroke and dementia and even more relevant because, in this growing age group, it is often neglected ${ }^{2}$.

In Brazil and in developed and some developing countries the demography profile is changing with increasing life expectation, thus the elderly comprise the fastest growing group of the population ${ }^{3}$. Currently 25 to $30 \%$ of new onset epilepsy is diagnosed in elders ${ }^{4,5}$. The prevalence of active epilepsy in the elderly is up to $1.5 \%$, almost three times higher than in younger adults, but among nursing home residents may exceed $5 \%^{2,6}$.

Epilepsy in the elderly presents several peculiarities that are unlike from epilepsy in younger individuals. Elders are at greater risk of cerebrovascular diseases, neurodegenerative and metabolic disorders that are associated with seizures occurrence. Special features of the treatment with antiepileptic drugs (AEDs) in the elderly arise from their physiologic

1Departamento de Neurologia, Hospital São Rafael, Salvador BA, Brazil;

${ }^{2}$ Departamento de Neurologia, Universidade Federal Fluminense, Rio de Janeiro RJ, Brazil.

Correspondence: Telma Rocha de Assis; Av. São Rafael, 2152; 41253-190 Salvador BA, Brasil; E-mail: telmasaj@gmail.com

Conflict of interest: There is no conflict of interest to declare.

Received 01 March 2014; Received in final form 25 July 2014; Accepted 15 August 2014. 
changes as from the pharmacokinetics and pharmacodynamics of these drugs. The pharmacokinetics of AEDs are complex in elderly patients owing to lower protein binding, impaired hepatic metabolism, altered volume of distribution, decreased renal clearance, and decreased enzyme inducibility $^{7}$. As a consequence of these age-related physiological changes, equivalent dosages would be expected to produce higher serum concentrations in elders than in younger patients. Adverse effects of AEDs are the most important issue in epilepsy management, especially among the elderly. Furthermore, some AEDs may exacerbate problems that are common in elders such as tremor, ataxia and cognitive difficult ${ }^{8}$. Elders often require medication for their comorbidities in addition to AED, so drug interactions should be a reason for concern. Thus, many epilepsy experts consider some old AEDs (phenobarbital, primidone and phenytoin) as inappropriate (suboptimal) drugs for elders and emphasize the need for careful choice of an appropriate AED for this population $^{7,9,10}$.

Prescription of AED is increasing as the prevalence of epilepsy rises and remains the mainstay of seizure prevention ${ }^{11}$. Despite the high incidence of epilepsy in the elderly and the increase in treatment options, there are few studies specifically focusing on the clinical use of AEDs in this population. Moreover, some studies of AED metabolism have been done in elderly, especially those who are frail.

The purpose of this study was to observe and characterize the prescribing patterns of AEDs regimen for hospitalized elderly with epilepsy as well their comorbidities and comedications. We also evaluated if AED treatment was according to the current clinical recommendations, practice guidelines and expert consensus opinion.

\section{METHOD}

Retrospective, cross-sectional study was performed on hospitalized elderly patients, with epilepsy and epileptic seizures in a tertiary center in Salvador (Bahia, Brazil). We defined elderly persons as individuals aged 60 years and above. All patients were under assistance of the neurology team. Data acquisition was carried out from January $1^{\text {st }}$, 2009 through December 31 ${ }^{\text {nd }}, 2010$. We analyzed charts of 782 elderly inpatients to ascertain prescribing patterns during length of hospitalization. They were admitted to the hospital for several neurological disorders. Of the total, 120 patients had previously diagnosed epilepsy (unprovoked seizures) or had new-onset epileptic seizures. Patients with acute symptomatic seizures (provoked seizures) were excluded from the study (11 patients). Overall, 109 patients who were under regular use of AED were selected to the study. In this sample, 39.4\% (43) of patients had been using AED previously to their admission and, the remaining had their onset of prescription during hospitalization. All patients were older than 60 years at the time of their first seizure. Epilepsy was the reason for AED prescription for all enrolled patients. The collected data were: age, gender, AEDs, types of seizures, comorbidities and potentially proconvulsant comedications. We categorized AED regimen based on clinical recommendation, mostly taking into account the adverse-effects profile of AEDs for this population of elderly inpatients, into two subgroups: group 1 defined as appropriate AEDs (carbamazepine, oxcarbazepine, valproic acid, gabapentin, clobazan and lamotrigine) and group 2 as inappropriate AEDs (phenytoin and phenobarbital). AED regimens included monotherapy and polytherapy (combination therapy with two or more AEDs).

This study was approved by the Ethics Committee of the Sao Rafael Hospital of Salvador, Brazil.

The statistical analysis was carried out with SPSS version 21.0. Percentages and the mean with standard deviations were used to express baseline data. Chi-square was used for comparative analysis among categorical variables in the group of appropriate and inappropriate AEDs, as well as monotherapy and polytheraphy. Statistical significance was defined as a p-value $<0.05$.

\section{RESULTS}

One hundred and nine patients $(90.8 \%$ / 120) were enrolled in the study (Figure 1). The mean age of the patients with new-onset epilepsy was $75 \pm 9$ years, $55 \%$ females.

Inappropriate AEDs, such as phenytoin and/or phenobarbital in combination with any AED, were the most prescribed AED regimen for more than two-thirds of patients $(\mathrm{n}=80)(73.4 \%$; $95 \% \mathrm{CI}=64 \%$ to $81 \%$; $\mathrm{p}<0.001)$ (Figure 2).

The most commonly used AED was phenytoin, in 53 patients (48.6\%; $95 \% \mathrm{CI}=39 \%$ to $58 \%$ ). Carbamazepine was

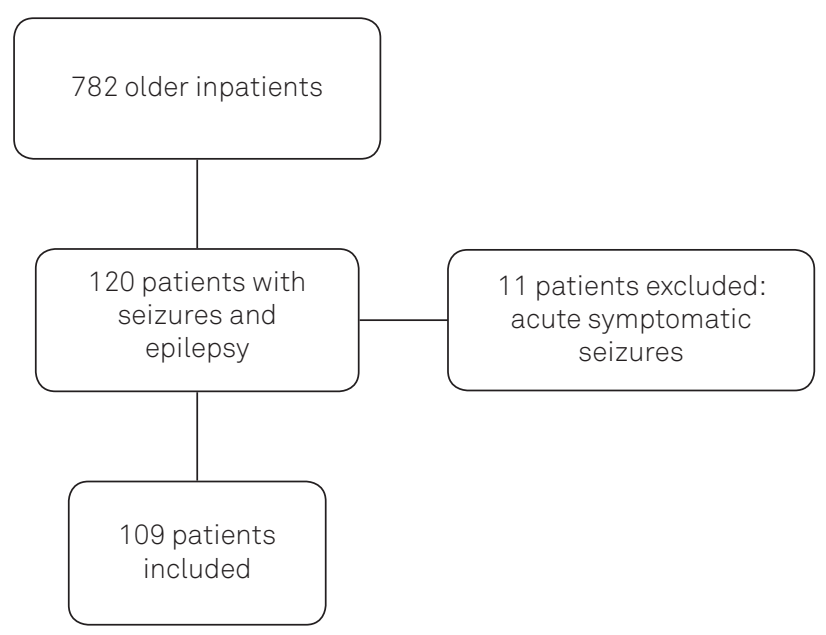

Figure 1. Study chart flow. 


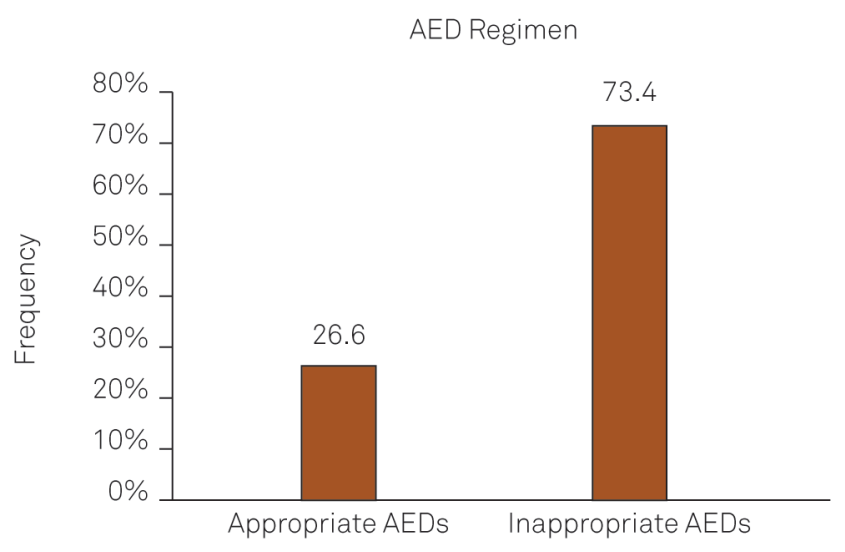

AED: antiepileptic drug.

Figure 2. Group 1 (Appropriate AEDs). Group 2 (Inappropriate AEDs).

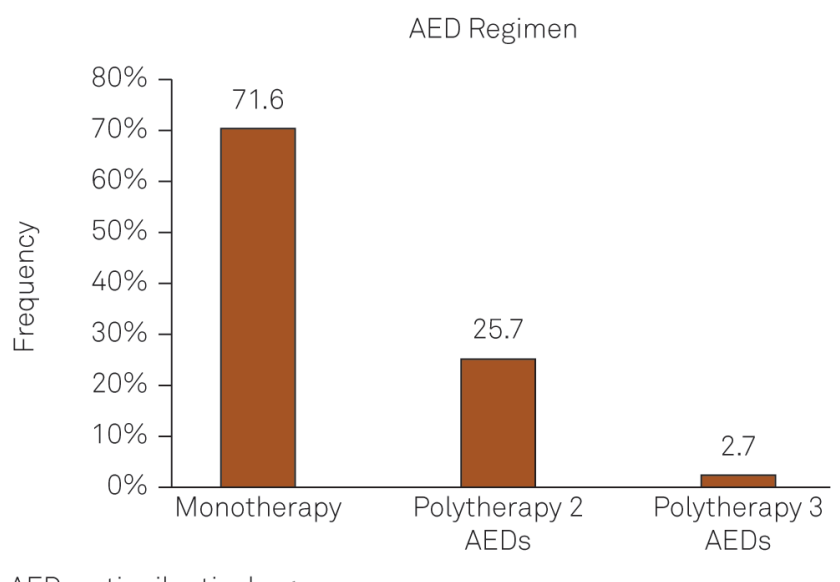

AED: antiepileptic drug.

Figure 3. AED Regimen subdivided in monotherapy and polytherapy.

Table 1. Frequency of prescribed AEDs.

\begin{tabular}{|c|c|c|c|c|c|}
\hline \multicolumn{2}{|c|}{ Group 1: Appropriate AEDs } & \multicolumn{4}{|c|}{ Group 2: Inappropriate AEDs } \\
\hline VP & $4.6 \%$ & $\mathrm{PHT}$ & $48.6 \%$ & $\mathrm{PHT}+\mathrm{CLB}$ & $0.9 \%$ \\
\hline LTG & $1.8 \%$ & PB & $0.9 \%$ & $P B+G B$ & $0.9 \%$ \\
\hline OXCBZ & $6.4 \%$ & $\mathrm{PHT}+\mathrm{PB}$ & $6.5 \%$ & $\mathrm{OXCBZ+PB}$ & $0.9 \%$ \\
\hline CBZ & $9.2 \%$ & $\mathrm{PHT}+\mathrm{VP}$ & $5.6 \%$ & OXCBZ+PHT & $0.9 \%$ \\
\hline $\mathrm{CBZ}+\mathrm{VP}$ & $2.8 \%$ & $\mathrm{PHT}+\mathrm{CBZ}$ & $2.8 \%$ & $P H T+V P+C L B$ & $0.9 \%$ \\
\hline $\mathrm{LTG}+\mathrm{CLB}$ & $0.9 \%$ & $\mathrm{PHT}+\mathrm{GB}$ & $0.9 \%$ & $\mathrm{PHT}+\mathrm{CBZ}+\mathrm{VP}$ & $0.9 \%$ \\
\hline $\mathrm{CBZ}+\mathrm{GB}$ & $0.9 \%$ & $\mathrm{PHT}+\mathrm{LTG}$ & $1.8 \%$ & $\mathrm{LTG}+\mathrm{OXCBZ+PHT}$ & $0.9 \%$ \\
\hline Total & $26.6 \%$ & & & & $73.4 \%$ \\
\hline
\end{tabular}

AEDs: Antiepileptic drugs; PHT: Phenytoin; PB: Phenobarbital; OXCBZ: Oxcarbazepine; VP: Valproic acid; CBZ: Carbamazepine; LTG: Lamotrigine; GB: Gabapentin; CLB: Clobazan.

the second most prescribed AED in monotherapy in 10 patients $(9.2 \%$; $95 \% \mathrm{CI}=5 \%$ to $16 \%)$ and when combined with other AED reaches $13.8 \%$ / 15 of patients. Lamotrigine was unless prescribed AED ( $\mathrm{n}=6)$ in mono and polytherapy (5.4\%; $95 \%$ CI $=2 \%$ to $12 \%)$ (Table 1). Most patients $(n=78)$ were in monotherapy $(71.6 \%$; $95 \% \mathrm{CI}=62 \%$ to $80 ; \mathrm{p}<0.001)$. Polytherapy with two and three AEDs were prescribed for $25.7 \%$ / 28 and $2.7 \%$ / 3 of patients, respectively (Figure 3).

The type of epileptic seizure was ascertained in 60.5\% / 66 of patients. Generalized seizures were described in 33\% / 36 of patients and focal seizures in $27.5 \%$ / 30 of them. Among the patients included in this study, $8.2 \%$ / 9 presented status epilepticus.

The most common comorbidities identified were systemic arterial hypertension (90\%) and systemic infections (40\%) followed by ischemic stroke, (38.5\%). Other comorbidities are displayed in Table 2.

Comedications with potential proconvulsant effects were used by approximately half of these patients $(n=54)(49.5 \%$; $95 \% \mathrm{CI}=40 \%$ to $59 \%$ ) and some of them had more than one of these prescribed drugs. Opioids pain killers, antiarrhythmics, B-blockers and antibiotics (quinolone and carbapenem) were the most prescribed potentially proconvulsant drugs (Table 3 ).

\section{DISCUSSION}

To our knowledge, this is the first study performed in Brazil, regarding prescribing patterns of AEDs for hospitalized elderly with new-onset epilepsy.

Although AEDs may be prescribed for many other conditions, such as neuropathic pain and psychiatric disorders, we limited our study to prescriptions issued to patients who had

Table 2. Most common comorbidities among 109 elderly inpatients in a tertiary center.

\begin{tabular}{lc}
\hline Comorbidity & Prevalence \\
\hline Arterial hypertension & $90 \%(98)$ \\
Systemic infections & $40 \%(44)$ \\
Ischemic stroke & $38.5 \%(42)$ \\
Diabetes mellitus & $33 \%(36)$ \\
Dementias & $25 \%(27)$ \\
Neoplasias & $23 \%(25)$ \\
Cardiopaties & $20 \%(21)$ \\
Toxic-metabolic & $19 \%(21)$ \\
Renal failure & $16 \%(17)$ \\
Haemorrhagic stroke & $12 \%(13)$ \\
Atrial fibrillation & $09 \%(10)$ \\
Hepatic insufficiency & $03 \%(03)$ \\
\hline
\end{tabular}


Table 3. Potencially proconvulsants comedications next to AEDs among 109 elderly inpatients in a tertiary center.

\begin{tabular}{|c|c|}
\hline Comedication & Incidence \\
\hline B-blocker ${ }^{28}$ & $7.6 \%(7)$ \\
\hline Diuretic (thiazide) ${ }^{28}$ & $5.4 \%(5)$ \\
\hline Opioid pain killer ${ }^{28}$ & $9.8 \%(9)$ \\
\hline Antiarrhythmic ${ }^{28}$ & $9.8 \%(9)$ \\
\hline Cephalosporin $3^{\text {th }}$ and $4^{\text {th }}$ generation ${ }^{28}$ & $4.4 \%(4)$ \\
\hline Penicilin derivative ${ }^{28}$ & $2.2 \%(2)$ \\
\hline Quinolone ${ }^{28}$ & $7.6 \%(7)$ \\
\hline Carbapenem ${ }^{28}$ & $5.4 \%(5)$ \\
\hline Aminoglycoside ${ }^{28}$ & $2.2 \%(2)$ \\
\hline Insulin 28 & $6.5 \%(6)$ \\
\hline TCAs (Imipramin, Nortriptyline) 28,29 & $3.3 \%(3)$ \\
\hline Phenothiazine ${ }^{28}$ & $1.0 \%(1)$ \\
\hline Olanzapine $e^{30}$ & $1.0 \%(1)$ \\
\hline Quetiapine $^{30}$ & $3.3 \%(3)$ \\
\hline Risperidone ${ }^{30}$ & $1.0 \%(1)$ \\
\hline Haloperidol ${ }^{28}$ & $1.0 \%(1)$ \\
\hline Levodopa $^{28}$ & $2.2 \%(2)$ \\
\hline Isoniazid 28 & $2.2 \%(2)$ \\
\hline
\end{tabular}

TCAs: Tryciclic antidepressant; AEDs: Antiepileptic drugs.

been diagnosed with epilepsy. The most prescribed AED regimen in this study was the group of inappropriate AEDs for $73.4 \%$ (80/109) of patients. We found that phenytoin, in monotherapy, was the drug of choice for these hospitalized elderly with epilepsy in $48.6 \%$ (53/109). When combined with other AEDs, phenytoin prescription reaches $70.5 \%(77 / 109)$. These findings were particularly unexpected because we found only a small number of patients (9/109) who presented status epilepticus, a condition for which intravenous medications are required, and could be one of the reasons for phenytoin administration during hospitalization. Our results are similar to other published studies in which phenytoin was the most frequently prescribed AED for elderly people with epilepsy (EPWE), despite its saturation kinetics and high potential interaction profile ${ }^{4,12,13}$. These studies were performed previously or very soon after the earliest published guidelines advising the use of the second generation AEDs for the treatment of elders with epilepsy. In the USA, a study conducted using National data from the Veterans Health Administration (VA) and Medicare to identify trends in AED prescribing for older patients with epilepsy found that phenytoin was the most commonly used AED (66.1\%) in spite of the growing number of clinical recommendations for other drugs 9 . A recent study conducted to evaluate clinical characteristics of patients with hospital-onset seizure, from 20 to 99 years old, has demonstrated that phenytoin was the most common AED prescribed de novo for $61 \%$ of patients both at seizure presentation and at discharge ${ }^{14}$. In our study carbamazepine, in monotherapy, was the second most prescribed AED for 9.2\% (10/109) of patients and lamotrigine was prescribed for small proportion of patients, 5.4\% (6/109).
A variety of factors may have contributed to scarce use of the newly AEDs in this population. First of all, the availability of few AEDs with suitable formulation for intravenous administration makes phenytoin the drug of choice when rapid seizure cessation is required; following this acute phase, usually it is maintained in its oral form until patient discharge. The lower frequency for carbamazepine prescription in this study is not clear even though this drug is marketed for over 30 years, has similar efficacy and cost to phenytoin and is well known by neurologists. Although lamotrigine has better tolerability, it requires slow titration which may hampers its prescription for hospitalized patients, especially for those requiring quick seizure control. Thus, this could be the reason lamotrigine had few number of prescriptions in our study. Indeed, the paucity of studies comparing phenytoin with newer AEDs in the elderly, may have contributed to the suboptimal prescription for this population.

Most patients had seizure remission with their first drug and become seizure-free on one AED (71.6\%); the remaining patients required polytherapy with either two or three AEDs. Monotherapy is the most appropriate regimen for epileptic patient, regardless of age and it is particularly interesting for older people ${ }^{8}$.

In total, $87 \%$ (95) patients of this study had multiple comorbidities. The most common were systemic arterial hypertension (90\%), systemic infections (40\%) followed by ischemic stroke (38.5\%) and diabetes mellitus (33\%). One study conducted for Austrian nursing home residents found that all of them had at least two comorbidities and these findings were confirmed by another Germany crosssectional study ${ }^{12,15}$. There are many reasons for concern when treating EPWE, in which the presence of multiples comorbidities (Table 2), such as arterial hypertension, systemic infections, stroke, diabetes mellitus, dementias, neoplasias, cardiopathies, etc., requires the need of comedications in addition to AED. EPWE, when hospitalized, are frailer than their counterparts and may be more at risk from adverse reactions of the AED even at standard doses on account of impaired drug elimination, physiological reduction in rate of drug metabolism and reduced seizure threshold. Malnutrition, rheumatoid arthritis, renal insufficiency are common conditions that may lower albumin levels and contribute to impair concentrations of protein-bound AEDs such as valproate and phenytoin. In this set, the use of polypharmacy is especially a problem because it increases risk of drug interactions, and even drug related deaths ${ }^{16,17}$. Moreover, the clearance of most first and second generation AEDs is reduced by about $20-40 \%$ in elderly patients compared with young adults ${ }^{18}$. Drugs that are renally cleared, such as gabapentin, pregabalin and levetiracetam are desirable because this results in fewer drug-drug interactions ${ }^{13}$.

In our study the patients were monitored clinically and merely $1.8 \%$ / 2 of them had measurement of serum 
AED concentrations. Serum AED concentrations may be important for dosage adjustment in elderly patient, however in the case of drugs that are highly proteins bound the level of pharmacologically active drug (fraction unbound) may be underestimated $^{18}$. For elderly patients treated with phenytoin, a highly protein binding AED, who have decreased serum albumin concentration, it is suggested that measuring free phenytoin levels may be a better indicator of efficacy and toxicity than total concentrations ${ }^{6}$. Moreover, phenytoin nonlinear pharmacokinetics and the capacity to induce or inhibit its metabolism can produce concentrations which may vary from sub therapeutic to toxic for some patients ${ }^{13}$.

Seizures induced by drugs are associated with use of comedications, high doses, parenteral administration and comorbidities ${ }^{4}$. In our study $41 \%(45 / 109)$ of patients had potentially proconvulsant comedications prescribed: $33 \%$ (36/109) received one drug and 8.25\% (9/109) got two drugs (Table 3). Compared to the Austrian study, where $91 \%$ of the residents were treated with at least one proconvulsant drug, our elderly inpatients perhaps received better level of care probably because they were assisted by neurologist during their hospitalization ${ }^{12}$.

Drug treatment for epilepsy changed in the last two decades mainly because of the progress in epilepsy clinical research and the development of several new drugs. Some of the standard AEDs, phenobarbital, primidone and phenytoin, identified as suboptimal AEDs for the elderly with newly diagnosed epilepsy, generally have a less favorable safety profile due to their side effects and potential drug interactions ${ }^{9,10}$. The other two standard AEDs, carbamazepine and valproate, have not been included in the suboptimal group for use in older patients in existing clinical recommendations ${ }^{9}$. Carbamazepine has simpler pharmacokinetics which makes it easier to adjust dosing, although incurs drug interactions, resulting in less severe adverse effects than phenytoin. In EPWE carbamazepine use should be a reason of concern because its propensity to induce the metabolism of other lipid-soluble drugs ${ }^{4,9,19}$. The AEDs with enzyme-inducing properties, such as carbamazepine, phenytoin and phenobarbital may promote drug-drug interactions which are particularly relevant for EPWE because usually they are under use of multiple medications to treat their comorbidities such as stroke, cardiovascular disease and neurodegenerative disorders. These enzyme-inducing AEDs may reduce the levels of drugs such as warfarin, donepezil, galantamine which is a further reason for care ${ }^{17}$. Many other drugs commonly used by EPWE are affected by enzyme inducers, such as calcium channel blockers and HMG-CoA reductase inhibitors (atorvastatin, lovastatin and simvastatin). Carbamazepine may have its level significant elevated when co-administrated with ticlopidine, verapamil and diltiazem. In addition, there is risk of phenytoin toxicity when administered with diltiazem ${ }^{17}$. Valproate should remain the drug of first choice for patients with generalized and unclassified epilepsies and has a low adverse effect profile in olders ${ }^{20}$. Valproate is associated with reduced protein binding and unbound clearance in the elderly, so clinical response may be achieved with a lower dose $e^{6}$. Furthermore, valproate has a beneficial mood stabilizing effect which may be appropriate for elderly with both disorders ${ }^{6,20}$.

The development of several new AEDs (gabapentin, lamotrigine, levetiracetam, oxcarbazepine, tiagabine, topiramate, zonisamide), that combine efficacy and low incidence of side effects has been improving the quality of care for epileptic patient ${ }^{10,11}$. These new second-generation drugs have more favorable pharmacokinetics such as low protein binding and no hepatic metabolization which minimize adverse effects and drug interactions ${ }^{21,22}$.

In the VA Cooperative \#428 Study, a randomized, doubleblind study of gabapentin, lamotrigine and carbamazepine in elderly community-dwelling epilepsy patients with newly diagnosed seizures, the authors concluded that lamotrigine and gabapentin should be considered as initial therapy for older patients with newly diagnosed seizures because their better tolerability and effective seizure control. In this study, hypersensitivity occurred more frequently with carbamazepine than with lamotrigine and hyponatremia occurred more frequently in carbamazepine than in gabapentin patients $^{23}$.

The SANAD study, Arm A, identified that lamotrigine was clinically better than carbamazepine because of its tolerability advantage and it was recommended as the AED choice for patients (children and people older 65 years) diagnosed with partial onset seizures ${ }^{24}$. An international multicenter randomized double-blind controlled trial of lamotrigine and sustained-release carbamazepine in the treatment of newly diagnosed epilepsy in the elderly showed comparable effectiveness, with trend for higher seizure-free rates for carbamazepine and better tolerability for lamotrigine ${ }^{25}$.

Updated review of ILAE, concluded that gabapentin and lamotrigine are established efficacious and effective as initial monotheraphy for elders with newly diagnosed or untreated partial-onset seizures ${ }^{26}$.

Guidelines from American Academy of Neurology, American Epilepsy Society and expert consensus opinions have been recommending the use of second-generation AEDs for the treatment of new-onset epilepsy in the elderly $^{27}$. These recommendations are based on available evidence regarding the potential deleterious effects of long-term enzyme induction with $\mathrm{AEDs}^{16}$. However, despite the relative tolerability and efficacy of the newer AEDs, they have similar efficacy when compared to first generations AEDs, are generally more costly and some of them are not available in poor-resources countries ${ }^{22}$. On the other hand, frequently the management of epilepsy in elderly people is inconsistent because initial drug selection is often made 
by primary care physicians with less experience in selection and adjusting the dosages of newer drugs. Indeed, inappropriate prescription for EPWE, is associated with negative health outcomes and economic consequences ${ }^{16}$. The treatment gap, meaning those people with active epilepsy not on treatment or on inadequate treatment is highly variable and is mainly attributed to lack of access to or knowledge of AEDs, poverty, cultural beliefs, delivery infrastructure and few trained physicians. The choice of drug in the majority of developing countries depends on availability and cost, so phenobarbital and phenytoin, despite their side effects, are still the most prescribed drugs in these countries.

Our study has several limitations due to its retrospective design implicating a restraint data acquisition. It is possible that some patients with epileptic seizures may not be included. On the other hand, because this population consists exclusively of hospitalized elderly patients, these patterns of care may not reflect the care for the general geriatric population in this institution. Besides, AEDs such as phenytoin, phenobarbital and valproic acid rather than lamotrigine, carbamazepine, oxcarbazepine, gabapentin, pregabalin and topiramate are available for use by parenteral route, which should have contributed to their choice in the hospital setting. Despite these limitations, this study contributes to provide knowledge on patterns of antiepileptic drug therapy for elderly inpatients with new-onset epilepsy in the light of current clinical recommendations for prescribing in this age-group.

Efforts should be done in order to raise the adherence to clinical practice guidelines for treating elderly patients with new-onset epilepsy. Therefore, this study argues for the need for more double-blind trials of AED treatment, in geriatric epilepsy patients.

We conclude that elderly inpatients in our tertiary center were mainly treated with inappropriate antiepileptic drugs, mainly phenytoin. The new generation AEDs was prescribed for a small number of patients. Furthermore, nearly half of the patients had potentially proconvulsant drugs prescribed as comedications.

As the population in most countries lives longer, the challenge is the appropriateness of prescribing older people with multiple chronic conditions and under use of multiple comedications.

\section{Acknowledgment}

We acknowledge Dr. Genoile Oliveira Santana Silva for her contributing in the statistical analysis.

\section{References}

1. Banerjee PN, Filippi D, Allen Hauser W. The descriptive epidemiology of epilepsy-a review. Epilepsy Res. 2009;85(1):31-45. http://dx.doi. org/10.1016/j.eplepsyres.2009.03.003.

2. Johnston A, Smith PE. Epilepsy in the elderly. Expert Review of Neurotherapeutics 2010;10:1899-910.

3. Assis TM, Costa G, Bacellar A, Orsini M, Nascimento OJ. Status epilepticus in the elderly: epidemiology, clinical aspects and treatment. Neurol Int. 2012;4(3):e17. http://dx.doi.org/10.4081/ni.2012.e17.

4. Stephen LJ, Brodie MJ. Epilepsy in elderly people. Lancet. 2000;355 (9213):1441-6. http://dx.doi.org/10.1016/S0140-6736(00)02149-8.

5. Trinka E, Bauer G, Oberaigner W, Ndayisaba JP, Seppi K, Granbichler CA. Cause-specific mortality among patients with epilepsy: results from a 30-year cohort study. Epilepsia. 2013;54(3):495-501. http://dx. doi.org/10.1111/epi.12014.

6. Leppik IE, Birnbaum AK. Epilepsy in the elderly. Ann N Y Acad Sci 2010;1184(1):208-24. http://dx.doi.org/10.1111/j.1749-6632.2009. 05113.x.

7. Waterhouse E, Towne A. Seizures in the elderly: nuances in presentation and treatment. Clev Clin J Med. 2005;72(Suppl3):S26-37. http://dx.doi. org/10.3949/ccjm.72.Suppl_3.S26.

8. Faught E. Monotherapy in adults and elderly persons. Neurology 2007;69(24 Suppl 3):S3-9. http://dx.doi.org/10.1212/01.wnl.0000302370. $01359.8 f$

9. Pugh MJ, Van Cott AC, Cramer JA, Knoefel JE, Amuan ME, Tabares J et al. Trends in antiepileptic drug prescribing for older patients with new-onset epilepsy: 2000-2004. Neurology 2008;70(22 Pt 2):2171-8. http://dx.doi.org/10.1212/01.wnl.0000313157.15089.e6.

10. Pugh MJ, Cramer J, Knoefel J, Charbonneau A, Mandell A, Kazis L et al. Potentially inappropriate antiepileptic drugs for elderly patients with epilepsy. J Am Geriatr Soc 2004;52(3):417-22. http://dx.doi.org/ 10.1111/j.1532-5415.2004.52115.x.

11. Nicholas JM, Ridsdale L, Richardson MP, Ashworth M, Gulliford MC Trends in antiepileptic drug utilisation in UK primary care 1993-2008: cohort study using the General Practice Research Database. Seizure. 2012;21(6):466-70. http://dx.doi.org/10.1016/j.seizure.2012.04.014.

12. Huber DP, Griener R, Trinka E. Antiepileptic drug use in Austrian nursing home residents. Seizure. 2013;22(1):24-7. http://dx.doi.org/ 10.1016/j.seizure.2012.09.012.

13. Collins NS, Shapiro RA, Ramsay RE. Elders with epilepsy. Med Clin North Am. 2006;90(5):945-66. ttp://dx.doi.org/10.1016/j.mcna.2006. 06.002

14. Fields MC, Labovitz DL, French JA. Hospital-onset seizures: an inpatient study. JAMA Neurol. 2013;70(3):360-4. http://dx.doi.org/ 10.1001/2013.jamaneurol.337.

15. Huying F, Klimpe S, Werhahn KJ. Antiepileptic drug use in nursing home residents: a cross-sectional, regional study. Seizure. 2006;15(3):194-7. http://dx.doi.org/10.1016/j.seizure.2006.02.002.

16. Brodie MJ, Mintzer S, Pack AM, Gidal BE, Vecht CJ, Schmidt D. Enzyme induction with antiepileptic drugs: cause for concern? Epilepsia. 2013;54(1):11-27. http://dx.doi.org/10.1111/j.1528-1167.2012.03671.x.

17. Levy RH, Collins C. Risk and predictability of drug interactions in the elderly. Int Rev Neurobiol. 2007;81:235-51. httpl://dx.doi.org/10.1016/ S0074-7742(06)81015-9.

18. Perucca E. Age-related changes in pharmacokinetics: predictability and assessment methods. Int Rev Neurol. 2007;81:183-99. http://dx. doi.org/10.1016/S0074-7742(06)81011-1.

19. Mattson RH, Cramer JA, Collins JF, Smith DB, Delgado-Escueta AV, Browne TR et al. Comparison of carbamazepine, phenobarbital, 
phenytoin, and primidone in partial and secondarily generalized tonic-clonic seizures. New Engl J Med. 1985;313(3):145-51. http://dx. doi.org/10.1056/NEJM198507183130303.

20. Marson AG, Al-Kharusi AM, Alwaidh M, Appleton R, Baker GA, Chadwic DW et al. The SANAD study of effectiveness of valproate, lamotrigine, or topiramate for generalised and unclassifiable epilepsy: an unblinded randomised controlled trial. Lancet 2007;369(9566):1016-26. http://dx.doi.org/10.1016/S0140-6736(07) 60461-9

21. Perucca P, Carter J, Vahle V, Gilliam FG. Adverse antiepileptic drug effects: toward a clinically and neurobiologically relevant taxonomy. Neurology 2009;72(14):1223-9. http://dx.doi.org/10.1212/01.wnl. 0000345667.45642 .61$.

22. Tatum WO. Antiepileptic drugs: adverse effects and drug interactions. Continuum (Minneap Minn) 2010;16 3 Epilepsy:136-58. http:// dx.doi.org/10.1212/01.CON.0000368236.41986.24.

23. Rowan AJ, Ramsay RE, Collins JF, Pryor F, Boardman KD, Uthman BM et al. New onset geriatric epilepsy: a randomized study of gabapentin, lamotrigine, and carbamazepine. Neurology 2005;64(11):1868-73. http://dx.doi.org/10.1212/01.WNL.0000167384. 68207.3E.

24. Marson AG, Al-Kharusi AM, Alwaidh M, Appleton R, Baker GA, Chadwick DW et al. The SANAD study of effectiveness of carbamazepine, gabapentin, lamotrigine, oxcarbazepine, or topiramate for treatment of partial epilepsy: an unblinded randomised controlled trial. Lancet. 2007;369(9566):1000-15. http://dx.doi.org/10.1016/ s0140-6736(07)60460-7
25. Saetre E, Perucca E, Isojärvi J, Gjerstad L. An international multicenter randomized double-blind controlled trial of lamotrigine and sustained-release carbamazepine in the treatment of newly diagnosed epilepsy in the elderly. Epilepsia. 2007;48(7):1292-302. http:// dx.doi.org/10.1111/j.1528-1167.2007.01128.x

26. Glauser T, Ben-Menachem E, Bourgeois B, Cnaan A, Guerreiro C, Kälviäinen $R$ et al. Updated ILAE evidence review of antiepileptic drug efficacy and effectiveness as initial monotherapy for epileptic seizures and syndromes. Epilepsia. 2013;54(3):551-63. http://dx.doi.org/10.1111/epi.12074

27. French JA, Kanner AM, Bautista J, Abou-Khalil B, Browne T, Harden $C L$ et al. Efficacy and tolerability of the new antiepileptic drugs II: treatment of refractory epilepsy: report of the Therapeutics and Technology Assessment Subcommittee and Quality Standards Subcommittee of the American Academy of Neurology and the American Epilepsy Society. Neurology. 2004;62(8):1261-73. http://dx. doi.org/10.1212/01.WNL.0000123695.22623.32

28. Ruffmann C, Bogliun G, Beghi E. Epileptogenic drugs: a systematic review. Exp Rev Neurother. 2006;6(4):575-89. http://dx.doi.org/ 10.1586/14737175.6.4.575

29. Hamid H, Kanner AM. Should antidepressant drugs of the selective serotonin reuptake inhibitor family be tested as antiepileptic drugs? epilepsy Behav. 2013;26(3):261-5. http://dx.doi.org/10.1016/j.yebeh. 2012.10.009

30. Alper K, Schwartz KA, Kolts RL, Khan A. Seizure incidence in psychopharmacological clinical trials: an analysis of Food and Drug Administration (FDA) summary basis of approval reports. Biol Psychiatry. 2007;62(4):345-54. http://dx.doi.org/10.1016/j.biopsych.2006.09.023 